\title{
La identidad masculina en Celestina: la emasculación de Pármeno
}

\author{
Amanda J. A. Tozer \\ University of Exceter
}

\begin{abstract}
Dado aue Celestina es un texto de autoría masculina, y fue dirigido a un público receptor predominantemente masculino (los colegas universitarios de Rojas), es de suponer que contenga representaciones de hombres que reflejen los diversos modelos de masculinidad medieval. Anne Laskaya $(1995,15)$ reconoce cuatro discursos de masculinidad medieval: el heroico o caballeresco, el cristiano, el amor cortés y el humanista, afirmando que: "different literary discourses of ideal heterosexual behaviour [...] were often in tension with another». Para Susan Crane, el concepto de la masculinidad en El cuento del caballero de Chaucer es motivo de gran tirantez:
\end{abstract}

Here as in many romances, men negotiate the difficult demand that they establish a heterosexual bond but maintain strong homosocial bonds by building the former into the latter, redoubling and extending masculine relations through courtship. (Crane 1994, 54)

Ante estas formulaciones, coincido plenamente con ambas autoras porque la perdición de Pármeno parece surgir de su seducción y su subsiguiente lucha para afirmar su masculinidad. En primer lugar, lo que me parece interesante de la afirmación de Laskaya es que señale claramente que tanto los hombres como las mujeres fueron sometidos al encasillamiento. En el caso de Pármeno, al no ser ni humanista, ni heroico, ni cristiano ni amante cortés, éste tiene que buscar su propia identidad o bien encajar con uno de estos modelos. Cualquier camino que escoja supone cierto grado de sacrificio personal. En segundo lugar, el planteamiento de Crane me parece importante porque hace hincapié en la incompatibilidad entre el papel «homosocial» del hombre y el deber de afirmar su virilidad. El eje de este concepto de masculinidad radica en la búsqueda de aprobación social mediante el sexo o el amor. Es decir, la igualdad y el compañerismo entre hombres sólo puede ser reforzada por la experiencia compartida del cortejo. En concreto, este rito de paso contribuye 
directamente a la creciente tendencia de Pármeno hacia la amoralidad. Pero, ¿cuáles son los factores que le conducen a abandonar la lealtad y la moralidad? ¿Hasta qué punto es culpable Pármeno?

Primeramente, me gustaría trazar las diferentes etapas en la trayectoria psicológica de Pármeno. Más adelante, analizaremos con profundidad los vínculos afectivos que mantiene o rompe Pármeno con los demás. Varios celestinistas como Deyermond (1961, 218), Hall Martin (1972, 71-134) y Severin $(1989,23-48)$ han analizado los ideales del amor cortés como un prototipo del discurso masculino. Sus estudios se han centrado en el diálogo y la conducta de Calisto como una parodia de estos ideales. No obstante, poco se ha escrito sobre la envergadura del estatus social y los ideales de Pármeno y cómo estos factores determinan el estilo y contenido de su diálogo. A mi juicio no se ha analizado suficientemente cómo estos factores afectan a su identidad. ${ }^{1}$ Para Gilman $(1982,100)$, las dramatis personae de Celestina podrían ser divididas en relaciones fijas como la de amo-criado, y "los tres dualismos advertidos por los críticos medievales de Terencio» tales como rico-pobre y viejo-joven. Asimismo, afirmó que estos referentes socio económicos y políticos de la comunicación dialógica podrían imponer ciertas limitaciones al individuo:

Por libre que sea el individuo para hablar o reaccionar en una forma adecuada a la situación o al encuentro peculiar del momento, hay ciertas cosas que no puede superar. Celestina tiene que hablar a Calisto o a Melibea o a Sempronio desde su vejez, desde su pobreza y desde su sexo, y nunca deja de hacerlo. (Gilman 1982, 101)

Esto es cierto particularmente en el caso de Pármeno, cuya faceta psicológica (y su diálogo) está condicionada por su posición en la sociedad como un criado joven. En relación a las diferencias entre los conceptos cristianos y humanistas de la masculinidad, Laskaya dice:

Like the discourse surrounding Christian masculinity, the humanist discourse privileged mind over body, but the goal was control of the world by knowledge and rational thought (Laskaya 1995, 18).

El diálogo de Pármeno parece encajar con esta amplia categoría, porque al igual que a Melibea, se le retrata no sólo como un individuo culto e instruido, sino además como un "pseudo-Aristotelian scholar» capaz de citar tanto a filósofos como a escritores profanos (Severin 1989, 4). A pe-

1. Conviene subrayar que no es mi intención infravalorar la importancia de estudios existentes sobre el carácter de Pármeno. Mi propósito es llamar la atención sobre ciertos aspectos del discurso de Pármeno que merecen mayor investigación Dorothy S. Severin proporciona una percepción biográfica de la relación entre Celestina y Pármeno en "Celestina: A Life», Celestinesca 25, 1-2 (2001): 101-106. 
sar de la premisa que la actitud de Pármeno hacia la vida es «estoico-moral», éste no da la impresión de ser un individuo impasible que se muestre indiferente a la emoción, sino que su doloroso pasado le ha llevado a interiorizar por fuerza sus emociones (Stamm 1977, 185). Hasta que se mencione el nombre de Areúsa a finales del Auto I, no hay antecedentes de lujuria en el enfoque de Pármeno sobre la vida, y podemos afirmar con toda seguridad que el diálogo de Pármeno no manifiesta signos patentes de heterosexualidad debido a la ausencia de tentación sexual.

Carlos Rubio propuso la siguiente interrogativa: "¿Quienes son los seductores y quienes los seducidos?» (Rubio 1978, 13). La respuesta a esta pregunta nos proporciona clara evidencia de complicidad entre Celestina, Calisto, y Sempronio (y luego, Pármeno) como seductores y transgresores de los códigos de conducta establecidos por la literatura. Estos personajes subvierten los paradigmas de masculinidad y feminidad presentados por la literatura amorosa medieval mediante las seducciones de Pármeno, Areúsa y Melibea. En primer lugar, a Pármeno le incitan a rebelarse contra la jerarquía masculina (Calisto) a fuerza de animarle a satisfacer sus pasiones. Aunque este tipo de comportamiento no era insólito entre los esclavos embusteros de la comedia romana, no tenía precedentes en la novela sentimental española. En segundo lugar, Areúsa se deja seducir por Celestina en beneficio de Pármeno, implicando de ese modo obediencia a un "superior» femenino. Esto es indicio obvio de una inversión de los papeles tradicionales de los personajes típicos en la literatura medieval, porque según la convención literaria, la ramera debe someterse a los deseos de un hombre dominante. En tercer lugar, Melibea es seducida por Celestina y Calisto (e indirectamente por Sempronio y Pármeno) y empujada a abandonar las virtudes asociadas con la preservación de su honor.

Motivados por la lujuria y la codicia, Calisto, Celestina y Sempronio recurren a diferentes formas de manipulación como la retórica, la coacción y la seducción, para realizar sus objetivos. La causa primordial de sus ideales materialistas y pasionales parece proceder de la creación de una contracultura para los amantes corteses, la cual ofrecía una alternativa al dogma religioso y a la moralidad del mundo medieval. En esta contracultura tan idealizada, la búsqueda del deseo se fomentaba con una larga tradición literaria de cuentos sobre amantes desventurados, tales como Píramo y Tisbe (Calisto, Auto I, p. 89), Dido y Eneas (Calisto, Auto vi, p. 183) y Paris y Elena de Troya (Pleberio, Auto xxi, p. 342). A pesar de que la gran mayoría de estas historias tengan un desenlace trágico, la noción del ennoblecimiento por el amor o la unión física continuaba popularizándose como una causa digna de seguir. En Celestina, esta causa depara una mina de lucrativas salidas comerciales para la clase baja alienada, la cual se aprovecha debidamente de esa moda. En el Auto I, a Celestina se le presenta un cliente nuevo - Calisto- quien percibe su amada Melibea 
como un artículo de lujo que no puede desperdiciar. Sin embargo, cuando Calisto decide que el amor ejerce una influencia más fuerte que el buen consejo de su siervo leal, Pármeno, se empeña en redefinir su descripción del trabajo para asegurar el resultado deseado. Asimismo, Celestina tiene que recurrir a su pericia como seductora para quebrantar la resolución de Pármeno, de allí que le eche el anzuelo sexual bajo el disfraz de Areúsa. Finalmente, la participación de Sempronio como cómplice de Celestina es clave en la evolución de l'affaire amoureuse. Como discutiré más adelante, la invocación de voces diferentes o estilos dialógicos por Pármeno corresponde directamente a los cambios que se van produciendo en su personaje y los autores dedican gran cantidad de «text-time» a su trayectoria psicológica. ${ }^{2}$

En el mundo creado artificialmente por Rojas, las relaciones sociales y sexuales se construyen y se invierten mediante el diálogo, es decir, los personajes afirman su femineidad y su masculinidad por lo que dicen y por su manera de decirlo. La repetición de lenguaje e imaginería estereotipada refuerza su identidad y crea expectativas de lo que van a decir o hacer. En otras palabras, la retórica de los personajes es a la vez una expresión de su identidad social y de su sexualidad. Además, en su lenguaje vemos reflejado el alcance de su socialización para hablar, actuar, y comportarse de una manera determinada. Sobre el tema de la virilidad y la violencia, Pierre Bourdieu apunta que los hombres son también víctimas de su representación dominante:

If women, subjected to a labour of socialization which tends to diminish and deny them, learn the negative virtues of self-denial, resignation and silence, men are also prisoners, and insidiously victims, of the dominant representation. Like the disposition towards submission, those which underlie the pursuit and exercise of domination are not inscribed in a nature, and they have to be learned through a long labor of socialization, in other words, as has been seen, of active differentiation from the opposite sex. (Bourdieu 2001, 49-50)

Desde el punto de vista del diálogo, Pármeno nos habla desde una posición de fortaleza moral, ya que sus virtudes masculinas se mantie-

2. Shlomith Rimmon-Kenan explica la diferencia entre "story-time» $y$ «text-time»: «time is not only a recurrent theme in a great deal of narrative fiction, but it is also a constituent factor of both story and text. The peculiarity of verbal narrative is that in it time is constitutive both of the means of representation (language) and of the object represented (the incidents of the story). Thus time in narrative fiction can be defined as the relations of chronology between story and text. [...] both story-time and text-time may in fact be no more than pseudotemporal. Nevertheless, as long as we remember their "pseudo" nature they remain useful constructs for the study of an important facet of the story-text relations.» Narrative Fiction: Contemporary Poetics, (London: Routledge, 1999): 44-5. 
nen relativamente intactas. Sus reacciones a las situaciones que se van revelando son respuestas condicionadas, que ha aprendido por un largo proceso de socialización. A pesar del hecho de que Pármeno parezca haber sufrido cierto grado de conmoción a causa de varios acontecimientos traumáticos en su vida, sus monólogos en el Auto I se caracterizan por dos posiciones de masculinidad y virilidad dentro del contexto del humanismo: razón y racionalidad. La razón de Pármeno se entiende como la capacidad de pensar y elaborar juicios y razonamientos sensatos. La racionalidad de Pármeno se revela como una base de conocimientos filosóficos, los cuales le llevan a considerar la razón como única fuente de conocimiento, haciéndole rechazar la emoción como una respuesta alocada. Privado de un modelo masculino y positivo a imitar, el sentido de identidad masculina de Pármeno parece estar basado en su función en la sociedad como criado y en consecuencia, su virilidad se define en concordancia con su eficiencia como un siervo fiel y un pensador racional. Desgraciadamente para Pármeno, estas virtudes no ganan el respeto de su amo, que las considera un obstáculo entre él y Melibea. Como resultado, Pármeno se enfrenta a un dilema complicado: si se mantiene firme, tendrá que plantearse el problema de alienación social e inseguridad, y si se reinventa en el molde de su nemesis, Sempronio, tendrá que aceptar su propia hipocresia. Sus largos monólogos en el Auto i son resueltos, autoritarios, y se pronuncian con un propósito muy claro: proteger a Calisto de Celestina, y por consiguiente, proteger sus propios intereses. La postura de Pármeno como un hombre que tiene sus emociones bajo control, se ve gravemente comprometida cuando Celestina le convence para que muestre su vulnerabilidad, su pasión, y sus sentimientos. Básicamente, al sustituir lo incorpóreo (lo espiritual/filosófico) por lo corpóreo (lo físico/ material), Pármeno se convierte en un siervo inútil. Obviamente, este es el lado negativo del privilegio masculino, parafraseando a Bourdieu, que afirma:

Male privilege is also a trap, and it has its negative side in the permanent tension and contention, sometimes verging on the absurd, imposed on every man by the duty to assert his manliness in all circumstances (Bourdieu 2001, 50)

\section{La relación madre-hijo}

Celestina es, indudablemente, la figura que más contribuye al desgaste del personaje de Pármeno, porque representa la influencia más perjudicial sobre su proceso decisorio. Ella no sólo obliga a Pármeno a revisar su estatus social, sino que le convence también para que rompa su vínculo 
afectivo y «homosocial» con Calisto para reemplazarlo por el amor fraterno de Sempronio. La relación entre Celestina y Pármeno gira entorno al trauma emocional, el miedo y el poder: el trauma asociado con las experiencias infantiles de Pármeno; su temor al abandono y a la inestabilidad; y el poder de Celestina para invocar estos temores y estas emociones con la memoria, y como afirma Bourdieu:

Manliness, it can be seen, is an eminently relational notion, constructed in front of and for other men and against femininity, in a kind of fear of the female, firstly in oneself (Bourdieu 2001, 53).

Teniendo en cuenta esta declaración, la actitud de Pármeno hacia Celestina surge como resultado directo del miedo que le inculca a él. La habilidad retórica de Celestina pronto se agota y al final acaba recurriendo a la seducción para ganar a Pármeno. No obstante, la fusión entre la retórica y la seducción no ocurre hasta que Celestina se da cuenta que sus estrategias más convencionales no le han surtido ningún efecto. Tras el trauma de haber sido abandonado por sus padres biológicos, Pármeno es sumido en el hampa macabro de Celestina. A pesar de que Celestina recuerde el tiempo que pasaron juntos en el contexto pseudo-familiar de una relación madre-hijo, es evidente que la experiencia de Pármeno bajo su custodia era distinta:

Celestina: Y yo ansí como verdadera madre tuya [...] (Ed. Severin 1998, 122)

PÁRmeno: [...] suplía en aquellos menesteres que mi tierna fuerça bastava. (110)

PÁRMENo: [...] y algunas vezes aunque era niño, me subías a la cabecera y me apretavas contigo, y porque olías a vieja, me huýa de ti. (120).

La manera en la que Pármeno justifica sus referencias a Celestina como una "puta vieja» en uno de sus famosos monólogos (Auto I, pp. 108-9) dejan al descubierto los síntomas de una neurosis a largo plazo causada por una experiencia angustiosa. Las numerosas descripciones proporcionadas por Celestina sobre la práctica de su madre Claudina como hechizera, parecen ser recursos biográficos y narrativos. Sin embargo, su persecución despiadada de Pármeno en el Auto vil desmiente esta conclusión: en realidad, es un ataque verbal de represalias. Su descarga de indignación sobre los comentarios desfavorables de Pármeno en el Auto I, se agudiza aún más a raíz de los apartes de Pármeno en el Auto vi. Por supuesto, las

3. Todas las citaciones de Celestina serán de la edición de Severin con notas en colaboración con Maite Cabello (Madrid: Cátedra, 1998). 
observaciones de la alcahueta acerca de los cambios en el porte físico y verbal de Pármeno son enteramente acertadas:

[...] y tú dasme el pago en mi presencia, pareciéndote mal quanto digo, susurrando y murmurando contra mí en presencia de Calisto. [...] Todavía me parece que te quedan reliquias vanas, hablando por antojo más que por razón. Desechas el provecho por contentar la lengua. (Auto vII, 192)

Al comienzo de la obra, el estilo dialógico de Pármeno se caracteriza por el poder de la razón: la lealtad es el factor predominante que sustenta su justificación lógica para proteger a Calisto, y se aprovecha de su propio intelecto y argumentación como base para sus acciones y decisiones en vez de sus emociones. Sin embargo, al llegar al final del Auto viI, su enfoque racional se deshace porque sus argumentos no eran lo suficientemente fuertes como para resistir sus propios instintos físicos. Este momento de ruptura coincide con su presentación a Areúsa. Como hemos visto, el autodominio de Pármeno no es nada más que el deseo reprimido, cosa que no podría controlar nunca con mera argumentación. En cambio, la táctica verbal de Celestina no es nada más que un intento de imponer un castigo a Pármeno a cambio de sus injurias. El hecho de que Celestina siga hostigando a Pármeno con información sobre su madre cuando éste ya había capitulado, ilumina una elaborada subestrategia: convencer a Pármeno que es una buena madre de alquiler. Celestina saca partido de sus memorias, ya sean reales o inventadas, para acusar a Pármeno de negar sus antecedentes familiares. Por lo tanto, los monólogos del «ciclo de Claudina» podrían ser interpretados como un esfuerzo de reconstruir la identidad de Pármeno. Queda patente que las virtudes relacionadas con el oficio de Pármeno son diametralmente opuestas a la inmoralidad de Celestina, Calisto y Sempronio, así pues, la infancia de Pármeno debe ser evocada de tal manera que implique una conexión a una vida de vicio, desenfreno y mal. Con esto, se espera que Pármeno interprete los cuentos de Celestina sobre el vínculo de su madre con la hechicería, como evidencia de una tendencia heredada hacia la conducta inmoral, haciéndole de este modo renunciar a Calisto de su obligación moral.

Por tanto, la eficacia retórica de Celestina parece estar arraigada en su capacidad de agotar a Pármeno y quebrantar su resolución, en vez de persuadirle con buena razón. Como consecuencia, la perseverancia y la profunda comprensión de la condición humana se revelan como componentes de la argumentación suasoria mucho más significativos que la retórica convencional. A pesar de la prolongada oposición de Pármeno a los trucos retóricos de Celestina, la magnitud de su sumisión a la voluntad de la alcahueta es indicativa del tipo de debilidad asociada por tradición con la conducta de la mujer en la literatura, tal como observa Anne Laskaya: 
If control and competition are hallmarks of masculinity within medieval gender discourse and are demonstrably pervasive issues surrounding men [...], obedience and rebellion mark key characteristics of femininity within that same discourse (Laskaya 1995, 141).

Ahora bien, ¿es la sumisión de Pármeno a Celestina evidencia de la paulatina emasculación de su frágil identidad? o ¿es, simplemente, una decisión de despedirse de su adolescencia y entrar en la mayoría de edad?

\section{La relación amo-criado}

En los Diferentes tipos de discurso difundidos durante la Edad Media tardía (el eclesiástico, el filosófico y el escolástico), la relación entre hombres de diferente edad subrayaba la subordinación del joven al mayor. Inevitablemente, cuando el estatus social representa el distintivo principal, como es el caso en la relación de Calisto y Pármeno, el criado es subordinado del amo y se ve privado del poder asociado con la nobleza. Aunque Pármeno renuncie a sus responsabilidades con Calisto como servus fidelis a regañadientes, la posibilidad de conquistar a Areúsa suscita un cambio radical en su actitud hacia el servicio a la clase dominante. Richard F. Green $(1980,112)$ afirma que: «the capacity to experience [romantic] love had long been regarded as an exclusively aristocratic prerogative.» Teniendo en cuenta esta propuesta, es muy probable que la decisión de Pármeno de rendirse a sus deseos latentes viniera acompañada por un motivo más siniestro: aseverar su superioridad psicológica sobre su amo, es decir, lograr una idea de masculinidad superior a nivel social y adquirir una cuota del poder. ${ }^{4}$ Como ya he señalado, la manipulación multifacética de Pármeno se sitúa en la alteración de la imagen que tiene de sí mismo. La persona de Pármeno está asentada en su papel social como criado de Calisto. Una vez despojado por Calisto de su capacidad por cumplir su deber social con relativo éxito, se convierte en un inútil y pésimo imitador de la conducta libidinosa de su amo. Al privarle de su única justificación para ser una persona honrada (servir a Calisto), sólo le quedan los instintos básicos asociados con cualquier otro hombre de su edad. Así pues, podríamos interpretar la decisión de Pármeno de unirse a Celestina y Sempronio como una contraofensiva diseñada para asegurar

4. Bourdieu respalda esta idea, afirmando que: "Manliness, understood as sexual or social reproductive capacity, but also as the capacity to fight and to exercise violence (especially in acts of revenge), is first and foremost a duty. Unlike a woman, whose essentially negative honour can only be defended or lost, since her virtue is successively virginity and fidelity, a "real» man is someone who feels the need to rise to the challenge of the opportunities available to him to increase his honour by pursuing glory and distinction in the public sphere.» Masculine Domination, (Cambridge: Polity, 2001): 51. 
la ruina de su amo criticón. Desde luego, el texto abunda en pistas para corroborar esta observación. En el Auto XII, Calisto pregunta a Pármeno si puede confirmar que su amada Melibea le está esperando, a lo que Pármeno responde:

¿Yo, señor? Nunca Dios mande que sea en dañar lo que no concerté; mejor será que tu presencia sea su primer encuentro, porque viéndome a mí no se turbe de ver que de tanto es sabido lo que tan ocultamente quería hazer, y con tanto temor haze, o porque quiçá pensará que la burlaste. (257)

Pármeno explota hábilmente el ansia de su amo para complacer a Melibea a cualquier precio, haciéndole caer en peligro con plena intención. Esto es una clara señal de una inversión irónica de estereotipos masculinos, porque el buen criado castiga a su amo por haber minado su juicio. ${ }^{5}$ Pármeno se nos presenta en Celestina como un individuo que no tiene una identidad abiertamente masculina en relación a su género; es, simplemente, un criado que encarna las cualidades de un hombre joven y moderadamente instruido durante la difusión del humanismo. El papel social de Pármeno no implica una conciencia de otros tipos de masculinidad medieval (salvo el amante cortés), porque éstos tienden a corresponder a clases sociales con las que Pármeno no ha tenido contacto. Su «autoimagen", como se desprende a lo largo de la obra, está construída casi por completo en torno a su función de servidor. Esto se debe en gran parte al hecho de que Pármeno fue privado de una figura paterna, pero en cambio, tuvo dos madres (Claudina y ahora, Celestina), ninguna de las cuales podrían ser descritas como modelos de conducta dignos de imitar. Consecuentemente, Pármeno ha tenido que luchar para conseguir su propia idea de lo que ser un hombre en la sociedad medieval realmente significa. En el Auto I, a Pármeno se le caracteriza como un chico sensato, sagaz y moderado, aunque conviene destacar que su resolución sólo empieza a desmoronarse cuando se permite entablar discusión con Celestina y Calisto. La perspectiva de un lío con Areúsa le facilita la oportunidad de explorar aspectos de su masculinidad previamente ocultos. Con esto Pármeno espera experimentar el ennoblecimiento mediante el amor, al igual que su amo. Al llegar al Auto xII, Pármeno ha consumado ya su amor por Areúsa y como resultado, su actitud hacia el amor en general le valen las alabanzas de Calisto: "¡O qué bien as dicho!; la vida me as dado con tu

5. Dorothy S. Severin acierta que «Like Rojas and unlike Calisto, Melibea and Pármeno are, at the beginning of Celestina, good readers of the Cárcel de Amor who distrust the disastrous effects of courtly passions. Melibea is also a good critic of a bad courtly lover like Calisto, and Pármeno a good critic of a bad master. But they too are brought to ruin when their passions are allowed to overwhelm their reason [...]», Tragicomedy and Novelistic Discourse in "La Celestina», (Cambridge: Cambridge University Press, 1989): 30-31. 
sotil aviso.» (257). Pero, esto resulta irónico por partida doble porque el consejo de Pármeno era malintencionado. Justo cuando Pármeno empieza a recoger los beneficios de lo que había sembrado, su muerte se hace inminente. Incluso cuando Pármeno ha demostrado su valor a los ojos de Calisto, su amo sigue aguijoneándole con sus réplicas pueriles: «¿Qué te parece, Pármeno, de la vieja que tú me desalabavas? ¿Qué obra ha salido de sus manos? ¿Qué fuera fecho sin ella?» (267).

Si prestamos nuestra atención a los episodios iniciales de diálogo entre Calisto y Pármeno (Autos I y II), un aspecto me parece de suma importancia: la carencia de verdadera comunicación interpersonal. A diferencia de la relación dialógica entre Calisto y Sempronio, Pármeno se ve continuamente privado de la oportunidad de debatir asuntos con su amo con profundidad. Calisto lo ha dejado muy claro que no valora el consejo de Pármeno y que prefiere la falsa expresión de lealtad de Sempronio por encima de su sinceridad. Calisto parece haber creado un sistema de doble filo para sus criados, en el cual sus funciones quedan claramente demarcadas: Sempronio ha sido designado como su consejero moral y por lo tanto, goza de un nivel más alto de responsabilidad. En comparación, la esfera de responsabilidad de Pármeno se limita a lo mundano; sea o no sea ésta una demarcación basada en la edad y en la experiencia es cuestionable, pero como apunta Alan Deyermond (2001, 18): «Pármeno is depicted as younger than Sempronio and with less intellectual awareness...». Esta observación se manifiesta en varios intervalos de diálogo corto entre Pármeno y Calisto. En el Auto v, Pármeno le avisa de la llegada de Celestina y Sempronio, los cuales describe entablados en una conversación viva. Pero Calisto rechaza sus observaciones de posible confabulación como erróneas y desacertadas y le insta a abrir la puerta:

PÁRMENo: ¡Señor, señor!

Calisto: ¿Qué quieres, loco?

PÁrmeno: A Sempronio y a Celestina veo venir cerca de casa, haziendo paradillas de rato en rato, y quando están quedos, hazen rayas en el suelo con el spada. No sé qué sea.

CAlisto: ¡O desvariado, negligente! Veslos venir, ¿no puedes baxar corriendo a abrir la puerta? ¡ $\mathrm{O}$ alto Dios, o soberana deidad! ¿Con qué vienen? ¿Qué nuevas traen? Que tan grande tardança que ya más esperava su venida que el fin de mi remedio. $¡ \bigcirc$ tristes oýdos, aparéjaos a lo que os viniere, que en boca de Celestina está agora aposentado el alivio o pena de mi coraçón! ¡ O si en sueños se passasse este poco tiempo, hasta ver el principio y fin de su habla! Agora tengo por cierto que es más penoso al delinquente esperar la cruda y capital sentencia que el 
acto de la ya sabida muerte. ¡ $\mathrm{O}$ espacioso Pármeno, manos de muerto! Quita ya essa enojosa aldava; entrará essa honrrada dueña, en cuya lengua está mi vida. (175-76)

Aunque el discurso corto de Calisto nos interesa principalmente por los ejemplos de presagio irónico, es también emblemático de su continuada subordinación de Pármeno. Su estatus como mero subalterno se recalca con el lenguaje peyorativo elegido por Calisto — «desvariado", "negligente», "espacioso", "manos de muerto»- de esta manera subrayando su propensión hacia Sempronio. Aunque conviene destacar que la enfermedad de amor podría ser la causa de la actitud retorcida de Calisto (tal como la hechizería desempeña un papel fundamental en la erosión de las facultades críticas de Melibea), la forma en la que despoja a Pármeno verbalmente es, sin duda, un factor contribuyente a la creciente agresividad y malicia de Pármeno hacia su amo. Asimismo, en el Auto vill, Calisto favorece abiertamente al juicio de Sempronio y demuestra un recelo de Pármeno. En el siguiente extracto de diálogo corto, el desvariado Calisto, absorto en un sueño, pregunta a Pármeno si es noche o día:

Calisto: ¿Es muy de noche? ¿Es hora de acostar?

PÁRmeno: Mas ya es, señor, tarde para levantar.

Calisto: ¿Qué dizes, loco; toda la noche es passada?

PÁrmeno: Y aun harta parte del día.

Calisto: Di, Sempronio, ¿miente este desvariado? ¿Que me haze creer que es de día. (219)

La relación dialógica entre Calisto y Pármeno nace de una necesidad de dirigirse el uno al otro, en vez de un deseo de comunicarse. Como amo, Calisto manda, reprende $y$, a veces, se deshace en elogios por Pármeno, pero casi nunca se hablan con gusto. A excepción de los monólogos de Pármeno en el Auto I, sus conversaciones son cortas y, a menudo, la interacción de Pármeno con su amo se reduce a unas cuantas interpolaciones. Esto se debe probablemente al hecho de que estos dos personajes no se gusten mucho; no manifiestan signos de respeto mutuo y tampoco tienen mucho en común. Es sumamente significativo que tanto Calisto como Pármeno se sienten obligados a hablar a espaldas el uno del otro, en vez de decirse las cosas a la cara. Hay dos motivos para esta conducta. Primero, cuando Pármeno intenta avisar a Calisto de entrar en negocios con Celestina se le tilda de entrometido, desleal y maldicente. Posteriormente, Pármeno se convierte en el enemigo que previene activamente a Calisto de obtener el objeto de su deseo. Esto le mueve a Calisto a cuestionar la lealtad de Pármeno y le lleva a pedir consejo a otro. Pármeno sufre el daño del repetido rechazo de su amo, de allí que procura consolarse con la relación engañosa con Sempronio y su relación sexual con Areúsa. 
De la misma manera que el acoso verbal de Celestina es una muestra de su ira y desconfianza, la reticencia de Calisto a entablar conversación con Pármeno es una manifestación de su sospecha. Parece que tanto Celestina como Calisto le atacan con afán de venganza, pero ninguno de ellos preve el tanteo final. En la relación entre Calisto y Pármeno, la desigualdad se exagera grotescamente; el reparto de papeles masculinos tradicionales queda invertido y en última instancia subvertido. El rechazo conduce a Pármeno a reevaluar su posición moral y acaba por escoger la amoralidad. Como apunta Jesús G. Maestro, el egotismo constituye uno de los referentes principales del discurso nihilista en Celestina, porque los personajes se esfuerzan deliberadamente por aseverar su individualismo, sin considerar las normas de conducta. Maestro dice lo siguiente con respecto al proceso decisorio de Pármeno:

Rechazado por Calisto, en sus deseos de prevenirle contra Celestina, Pármeno se siente defraudado: la moral del virtuoso no sirve para triunfar en la sociedad humana. Decide entonces, estimulado por un resentimiento hacia su amo, aceptar, a cambio de prosperidad, el camino alternativo de degeneración moral que le ofrecen Sempronio, Celestina y Areúsa (Maestro 2001, 66).

Hasta cierto punto, Pármeno ha tratado de vengarse al emular la conducta de Calisto, pero resulta ser un imitador pésimo de un amante inepto, y un patrón aún más inútil. Lejos de redoblar y profundizar su relación masculina con Calisto por vía del cortejo, no le lleva más cerca al ennoblecimiento y tampoco hay pruebas de solidaridad ni de compañerismo como resultado de sus experiencias paralelas. El resultado es que los conceptos tradicionales de la masculinidad medieval ponen en plena evidencia la incompatibilidad del comportamiento de las figuras masculinas en Celestina. Calisto debe representar un modelo positivo a imitar y un ejemplo de masculinidad distinguida y honrada, pero decide traicionar a Pármeno, de este modo agravando su perdición. Con esto, Pármeno le abandona y encuentra que puede identificarse mejor con su álter ego corrompido, Sempronio.

\section{La influencia fraterna}

Tras ser ReCHAZADo por su amo y escogido como víctima de Celestina, Pármeno encuentra algo de consuelo en su relación con Sempronio, que sí es redoblada mediante su lío con Areúsa. Esta relación le ofrece la oportunidad de desahogar su ira y frustración de haber sido objeto de abuso y ostracismo de sus presuntos protectores. A pesar de su impropiedad, Sempronio se convierte en un guardián suplente o un hermano de alqui- 
ler, mientras que Pármeno empieza a copiar su conducta y lenguaje con el afán de afirmar su masculinidad y obtener la aprobación de sus contemporáneos. No obstante, ninguno de los hombres en Celestina que tiene contacto directo con Pármeno puede servirle como un ejemplo de masculinidad virtuosa y como consecuencia, la «autoimagen» de Pármeno junto con su imagen pública se reconstruye alrededor de dos ideas polarizadas de identidad masculina: el amante cortés (Calisto) y el criado/consejero moral (Sempronio). Desgraciadamente para Pármeno, ambos modelos de conducta e identidad masculina se someten a una distorción grotesca por los mismos personajes a los que corresponden. El resultado es que Pármeno acaba imitando un patrón de mala conducta y se equivoca al creer que esa conducta será un vehículo para la atribución de poder; convirtiendo así en una imposibilidad su lucha por adquirir atributos positivos masculinos. Este proceso se agrava aún más con la seducción de Pármeno, la cual representa una pérdida simbólica de inocencia y adolescencia, y es el factor que más contribuye a su perdición.

\section{La relación hombre-mujer}

Celestina se aprovecha de la curiosidad natural de Pármeno sobre el sexo opuesto para asegurar su éxito en el trato comercial con Calisto; cosa que sella con la iniciación de Pármeno en su subcultura de amor. Celestina emplea hábilmente este rito de tránsito como una prueba de su virilidad. A mi parecer, la claudicación moral de Pármeno sólo puede ser interpretada como un intento de reforzar su solidaridad con los demás personajes masculinos. Pármeno está enamorado de la idea de estar enamorado, y es un tipo de creencia específica que ha aprendido de su amo. La mención del nombre de Areúsa (Auto I, 124) le hace descender en espiral a la obsesión sexual con alguien que ni siquiera ha conocido. Está claro que su curiosidad sobre las mujeres se deriva de la ausencia de cualquier contacto positivo con el sexo opuesto, y como dice Stephen Gilman:

Pármeno, a diferencia de Sempronio y de Calisto, no considera a las mujeres ni como divinas ni como infrahumanas, sino como un misterio vedado. Su sentimiento no consiste en una aversion racional, ni tampoco en una adoración sin freno; es más bien curiosidad de los sentidos, disimulada por la pedantería (Gilman 1982, 103-04).

$\mathrm{Su}$ inexperiencia y su absoluta falta de comprensión de las mujeres, le lleva a objetivar a Areúsa como una mujer lasciva con un apetito insaciable. El autoengaño de Pármeno levanta su confianza, permitiéndole mantener la ficción de nuevas y renovadas relaciones sexuales. Lejos de 
ennoblecerse y experimentar un sentido de liberación personal, Pármeno es completamente emasculado:

¡O plazer singular, o singular alegría! Quál hombre es ni ha sido más bienaventurado que yo, qual más dichosa y bienandante, ique un tan excellente don sea por mí posseýdo, y quán presto pedido tan presto alcançada! Por cierto, si las trayciones desta vieja con mi coraçón yo pudiesse suffrir, de rodillas avía de andar a la complazer. (212)

La repetición del adjetivo "singular» se pronuncia con la intención de reflejar la euforia de Pármeno, pero es posible que Rojas lo haya repetido para recalcar la singularidad literal de su experiencia como un hecho aislado que no se convertirá nunca en una relación de veras. De hecho, es de suma importancia que Areúsa no admita la presencia de Pármeno en el Auto IX, ni mantenga nuevas relaciones con él. En realidad, su experiencia le ha hecho ponerse metafóricamente de rodillas: Pármeno ahora se muestra dispuesto a adoptar un papel aún más sumiso en su relación con Celestina, utilizando su lío con Areúsa como pretexto para trabar amistad con Sempronio.

\section{Conclusión}

PÁRMENO NO CONSIGUE aseverar su masculinidad de una manera virtuosa y digna. Este fracaso puede ser entendido como una pérdida paulatina de control y una rendición al placer carnal. Calisto, Sempronio y Celestina conspiran contra Pármeno "para convertir el imposible ideal de virilidad en una fuente de vulnerabilidad inmensa. ${ }^{6}$ Colectivamente, juegan con su temor a perder el respeto del grupo para incitarle a la imprudencia. Aunque Pármeno manifiesta signos perceptibles (externos) de masculinidad, - capacidad sexual y violencia - paradójicamente, se transforma en la encarnación de la debilidad. Rojas plasma este proceso en su texto con meticulosidad, desarrollando la técnica de gradatio para hacer hincapié en la degeneración de Pármeno por una caída retórica sostenida en su estilo dialógico. La dependencia inicial de Pármeno en las sentencias escolásticas se revela como poco más que un barniz de ingenuidad que le había protegido de los vicios del mundo real. Al quitar esta capa superficial de autoridades antiguas, Rojas podía exponer la incompetencia del sujeto con mayor atención al detalle, además de explorar la oposición entre la razón y la emoción - la psicología del lenguaje de Pármeno- con más profundidad. Su remate final de supuesta valentía está arraigada en una especie de debilidad emocional: la cobardía. Ésta se presenta como un 
temor a la exclusión del mundo de los hombres, el cual queda hecho pedazos al final de la obra.

\section{Bibliografía citada}

BOURDIEU, Pierre, Masculine Domination (Cambridge: Polity, 2001).

CRANE, Susan, Chapter I: "Masculinity in Romance» in Gender and Romance in Chaucerss Canterbury Tales (New Jersey: Princeton University Press, 1994).

DEYERMOND, Alan, "The Text-Book Mishandled: Andreas Capellanus and the Opening Scene of La Celestina». Neophilologus XXXXV (1961): 218-221.

- «Readers in, Readers of, Celestina». Bulletin of Hispanic Studies LXXVIII (2001): 13-37.

GILMAN, Stephen, La Celestina: arte y estructura, Spanish translation by Margit Frenk de Alatorre (Madrid: Taurus, 1982).

GREEN, Richard F., Poets and Princepleasers: Literature and the English Court in the Late Middle Ages (Toronto: University of Toronto Press, 1980).

HALL MARTIN, June, Love's Fools: Aucassin, Troilus, Calisto and the Parody of the Courtly Lover (London: Tamesis, 1972).

LASKAYA, Anne, "Dominant Medieval Discourses on Gender» in Chaucer»s Approach to Gender in the Canterbury Tales, Chaucer Studies, vol. XXIII (Cambridge: D. S. Brewer, 1995).

MAESTRO, Jesús G., El personaje nihilista: "La Celestina» y el teatro europeo (Madrid and Frankfurt: Iberoamericana/Vervuert, 2001).

RIMMON-KENAN, Shlomith, Narrative Fiction: Contemporary Poetics (London: Routledge, 1999).

ROJAS, Fernando de, La Celestina, edition by D.S. Severin and notes in collaboration with Maite Cabello (Madrid: Cátedra, 1998).

RUBIO, Carlos, «El juego de seducciones de La Celestina. Una estructura dramática», Celestinesca 2, 1 (1978): 13-23.

SEVERIN, Dorothy S., "Genre and the Parody of Courtly Love», in Tragicomedy and Novelistic Discourse in "La Celestina" (Cambridge: Cambridge University Press, 1989).

- «Celestina: A Life», Celestinesca 25, 1-2 (2001): 101-106.

- «Aristotle»s Ethics in La Celestina». La Corónica X, I (1981): 54-58.

SNOW, Joseph T., "iCon qué pagaré esto?: The Life and Death of Pármeno» in The Age of the Catholic Monarchs, 1474-1516. Literary Studies in Memory of Keith Whinnom, edited by Alan Deyermond and Ian Macpherson, Bulletin of Hispanic Studies, Special Issue (Liverpool: Liverpool University Press, 1989): 185-92.

STAMM, James R., "El tesoro de Pármeno", La Celestina y su contorno social, Actas del I Congreso Internacional sobre La Celestina, with an introduction by Manuel Criado de Val (Barcelona: Borrás Ediciones, 1977): 185-191. 
Tozer, Amanda J. A., «La identidad masculina en Celestina: la
emasculación de Pármeno», Celestinesca 27 (2003), pp. 149-164.

\section{RESUMEN}

ESTE ARTICULO pretende analizar con profundidad los vínculos afectivos que mantiene o rompe Pármeno con los demás con el objetivo de arrojar luz sobre la perdición de Pármeno y su subsiguiente lucha para aseverar su masculinidad de una manera circunspecta. El eje de este estudio gira en torno a los cambios que se van produciendo en el estilo dialógico de Pármeno, interpretados como consecuencia directa del conflicto interno que experimenta éste al sustituir la razón por la emoción, en un afán de ganar la aprobación de sus contemporáneos masculinos por vía de la experiencia compartida del cortejo.

PALABRAS CLAVE: Celestina, masculinidad medieval, razón-emoción, rechazo, aprobación, venganza.

\section{ABSTRACT}

THIS ARTICLE seeks to shed new light on Pármeno's dramatic downfall and his subsequent failure to assert his masculinity in a dignified manner by analysing in depth the principle relationships which he maintains or breaks with the other characters. The central argument of this article focuses on the changes in Pármeno's dialogic style(s), which are interpreted as direct consequences of the internal conflict brought about by his decision to substitute reason with emotion, in an attempt to win the approval of his male contemporaries via the shared experience of courtship.

KEY WORDS: Celestina, medieval masculinity, reason-emotion, rejection, approval, revenge.

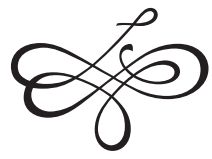

